\title{
HAS ARCTIC SEA ICE RAPIDLY THINNED?
}

\author{
Greg Holloway and Tessa Sou
}

Institute of Ocean Sciences, Sidney, B.C., V8L 4B2, Canada

tel: +1(250) 363-6564, fax: +1(250) 363-6746,e-mail: hollowayg@pac.dfo-mpo.gc.ca

submitted: June 7, 2001

revised: Oct 23, 2001 


\section{ABSTRACT}

Reports based on submarine sonar data have suggested Arctic sea ice has thinned nearly by half in recent decades. Such rapid thinning is a concern for detection of global change and for Arctic regional impacts. Including atmospheric timeseries, ocean currents and rivers runoff into an ocean-ice-snow model shows the inferred rapid thinning was unlikely. The problem stems from undersampling. Varying winds which readily redistribute Arctic ice create a recurring pattern whereby ice shifts between the central Arctic and peripheral regions, especially in the Canadian sector. Timing and tracks of the submarine surveys missed this dominant mode of variability. Although model-derived overall thinning from the 1960s to 1990s was less than hitherto supposed, there is also indication of accelerated thinning during the early-mid-1990s. 


\section{INTRODUCTION}

Concern for possible global warming focuses attention on the Arctic where changes may become apparent more quickly than at lower latitudes. Arctic sea ice is both an indicator of change and a mechanism, affecting global climate by insulating the winter atmosphere from a warmer underlying ocean, by ice-albedo feedback, and by influencing the stability of oceanic thermohaline overturning. In this paper we explore how observations, theory and modeling work together to clarify perceived changes to Arctic sea ice.

Ice extent has been estimated from satellite observations since 1973 (Carsey, 1982). Analyses of total areal extent have showed a statistically confident decrease at about 3\% per decade during 1979 to 1998 (Cavalieri et al., 1997; Johannessen et al., 1999; Parkinson et al., 1999; Vinnikov et al., 1999; Serreze, et al., 2000).

Ice thickness has been more difficult to observe. Early reports from observations near the North Pole, taken by various means at different times of year (Shy and Walsh, 1986; McLaren et al., 1992), did not show significant trends. Broader coverage of the Arctic domain has resulted from submarine-based sonar profiling (Bourke and Garrett, 1987; Bourke and McLaren, 1992; Rothrock et al., 1999; Wadhams and Davis, 2000; Winsor, 2001; Tucker et al., 2001). A startling result from submarine profiling, reported by Rothrock et al. (1999, hereafter RYM) and supported by Wadhams and Davis (2000, hereafter WD), was that average thickness decreased more than $40 \%$ over a few decades. Specifically, RYM found that, averaging over five cruises in autumns of 1958, 1960, 1962, 1970 and 1976 and averaging over three cruises in autumns of 1993, 1996 and 1997, the latter average showed 42\% less ice volume than the former average. Comparing single cruises in 1976 and 1996, WD found a strikingly similar reduction in ice volume by $43 \%$ over 20 years, this near a region where Wadhams (1990) previously reported 15\% loss of ice volume between 1976 and 1987. However, six submarine cruises from Alaska to $90 \mathrm{~N}$ during 1991 through 1997, showed almost no average thinning (Winsor, 2001). From nine cruises from 1976 through 1994 on the Alaska to 90N section, Tucker et al. (2001, hereafter TWEFB) 
found abrupt thinning between 1988 and 1990, prior to the period examined by Winsor. TWEFB remarked that thinning did not occur near 90N, agreeing with Shy and Walsh (1986) or McLaren et al. (1992) but contrasting with RYM or WD. All these data locations are shown on Figure 1.

Given the different time periods and locations of data, the different results are not contradictory. An overall perception is that the volume of Arctic sea ice has suffered rapid multi-decadal decline, e.g., as read in the IPCC 2001 assessment where loss of autumn sea ice by more than $40 \%$ was deemed "likely" ( $66 \%$ to $90 \%$ likelihood). Such rapid loss of sea ice attracted widespread attention among environmental scientists and in popular media. Because of the importance of the issue both for global change studies and for regional Arctic impacts, and because of differences among the reported observations, we seek other sources of information which may provide a more comprehensive view. We incorporate data from the atmosphere, rivers and ocean along with dynamics expressed in an ocean-ice-snow model.

\section{DYNAMIC CONSTRAINTS ON INFERRED CHANGES OF ICE VOLUME}

Is apparent decline of Arctic ice volume consistent with plausible physical mechanisms? RYM considered three possibilities. First, warming may enhance ice melt and reduce ice growth. Second, changes to snow cover affect net ice growth. Third, varying ice export at Fram Strait alters the ice volume remaining within the Arctic. Interactions among these and other mechanisms can be further quantified in numerical models. From ocean-ice-snow modeling, Zhang et al. (2000, hereafter ZRS) identified spatial variations in wind-forced ice distributions that affect overall growth/melt through feedbacks involving open water fraction and ice-albedo. Using an ice-only model forced by wind and air temperature (no precipitation), Hilmer and Lemke (2000, hereafter HL) also found decreasing ice volume which appeared to respond more to wind than to air temperature. An important further perspective is seen in ocean-ice-snow modeling by Polyakov and Johnson (2000, hereafter PJ) where the volume of ice over the entire Arctic showed no significant trend as decreases in the central Arctic (sampled by submarines) were compensated by increases elsewhere. 
There are many uncertainties. Observations of ice thickness depended upon different methods of sonar operation, non-coincident cruise tracks and differences of seasonal timing among cruises, cf. RYM and Wadhams (1997). Model results depend upon uncertain timeseries of varying winds, changes of radiative forcing, precipitation and heat transport by ocean currents along with a host of uncertain internal parameterizations.

The goal in this paper is to complement sparse observations with results from ocean-icesnow modeling. To account for model uncertainty with respect both to incomplete physics and to poorly known initial, boundary and forcing conditions, we execute a range of cases using different choices of internal model parameters and different estimates of atmospheric forcing. Our focus is upon robustness, seeking physically consistent constraints that may refine inferences from sparse observations. As well, model output is used to assess natural variability, identifying dominant modes of Arctic sea ice change.

The numerical model follows Nazarenko et al. (1998), consisting of 3D ocean with dynamic-thermodynamic sea ice and snow on a spherical finite difference grid. Among changes since Nazarenko et al. (1998), the present model omits flux correction (surface layer restoring). We apply atmospheric forcing from NCEP/NCAR (Kalnay et al., 1996) with river inflows from Becker (1995), and initial ocean conditions from PHC (Steele et al., 2001). The domain has open boundaries across Bering Strait, Baffin Bay and the Greenland-Norwegian Sea. Specification of open boundary conditions and further model details are listed in an appendix.

Integrations were initialized over 30 years of climatological annual cycle, followed by 52 years (1948 through 1999) monthly atmospheric forcing, adjusted for daily wind variability. Among uncertainties in forcing fields, especially we find results sensitive to estimated evolution of windstress. Within the set of NCEP atmospheric variables, there are different ways to estimate windstress. First, there is reanalysis windstress. Second, NCEP supplies 10m vector wind which, with estimated windspeed and surface parameters, can be used to calculate stress. Third, NCEP reanalyses of sea level pressure can be used with empirical parameterizations to estimate "geostrophic windstress". Stress estimated from sea level pressure have been constructed both from monthly pressure, with stress magnitude rescaled from daily windspeed, and from daily pressure. Details of windstress and windspeed estimation are discussed by 
Steiner et al. (2001). We have also explored uncertainty to internal model parameters such as ice strength, leads fraction and downward longwave radiation. Among cases illustrated in this paper, we compare the Parkinson and Washingon (1979) with König-Langlo and Augstein (1994) parameterizations of downward longwave. Figure 1 shows a sample 52 year annual mean ice thickness over a domain for which ice budgets will be evaluated, with ice fields blanked outside the evaluation domain, e.g., excluding Baffin Bay or Greenland Sea. Locations of submarine data are indicated.

Over the range of numerical experiments we found modest reductions in ice area, as also estimated from satellite data. The same experiments exhibited only moderate loss of ice volume by amounts much less than reported by RYM or by WD. This raises a question if something is fundamentally wrong in the model dynamics, or in the applied forcing, or if inferences from submarine data have yielded a mistaken impression of overall Arctic ice volume. In part we explored the range of model cases to search for possible sources of model error. Although minor deficiencies were suggested, the search for sources of model errors (subjects of continuing study) produced no clear results. Hence we ask instead how results from submarine data may not have represented the larger Arctic.

\section{CRUISING IN VIRTUAL SUBMARINES}

Loosing "virtual submarines" to sample the model Arctic at the times and places of the actual submarine cruises, we revisit first RYM. In their study, RYM identified 29 locations at which coincidence of tracks and adjusted seasonal timing were adequate to support comparisons. Those 29 locations are plotted in Figure 2 on a map of model difference between September ice thickness averaged over 1993, 1996 and 1997 less September thickness averaged over 1958, 1960, 1962, 1970 and 1976.

In the case shown in Figure 2, reduction of ice volume as sampled by virtual submarines at RYM times and places was 31\% while RYM reported $42 \%$. Other cases show reductions sampled at RYM times and places varying from $25 \%$ to $43 \%$. The pattern of change in Figure 2 can be compared with the pattern in Figure 4 of RYM. There are differences as model thinning is 
more evident in the Canada Basin while RYM showed greater thinning in the Nansen Basin. The model pattern is robust across the range of model cases, albeit differing in details. Overall it appears that the location and timing of submarine data used by RYM coincided with locations of thinning while substantial thickening occured elsewhere, especially nearer Canada where US submarines were excluded. While modelled thinning at RYM locations and dates ranged from $25 \%$ to $43 \%$, the anaysis domain showed total thinning by lesser amounts ranging from $12 \%$ to $15 \%$. Moreover, as will be discussed in Section $4 \mathrm{c}$, even this lesser amount is quite specific to the timing of observations.

We have further decomposed domain volume loss (12\% to $15 \%)$ over the RYM period into two parts, one due to thermodynamic changes (net growth and melt) and one due to changing export. Across the range of cases studied, loss during this period was dominated by windinduced greater export (principally via Fram Stait).

Similarly to the analysis concerning RYM, we have sampled along the approximate line reported by WD and in the sector reported by Winsor and by TWEFB. In the case of WD, two cruises between Fram Strait and 90N in Sept-Oct of 1976 and 1996 were found to show decrease of ice volume by $43 \%$, remarkably similar to the $42 \%$ loss reported by RYM from eight cruises through the larger Arctic. Our range of model results show the Nansen Basin region to be highly sensitive, as we obtain volume losses along the WD line from $28 \%$ to $73 \%$. Differencing between fall 1996 and 1976, total ice volume over the analysis domain decreased between 27\% and 36\%, values not so different from the $43 \%$ which is specific to the line reported by WD. A caution is that this represents only differences between two points in time.

From six cruises between Alaska and 90N from 1991 through 1997, Winsor found no discernable trend in ice volume. These data are more difficult to evaluate however because three cruises in 1991, 1992 and 1994 occurred during spring, near time of maximum ice, while three cruises in 1993, 1996 and 1997 occured in late autumn near time of minimum ice. Winsor was obliged to attempt to adjust autumn cruises to late spring by adding $0.9 \mathrm{~m}$ after a model-derived thickness cycle (RYM). Along the Winsor track, model cases show a volume loss, such that differences between May 1997 and 1991 fall in the range 7\% to 24\% (for which difference Winsor shows $9 \%$ loss). For this time period we obtain more rapid total loss (10\% to $21 \%$ ) over 
the analysis domain.

Examining nine cruises between Alaska and 90N, all in late spring from 1976 through 1994, TWEFP find a large (32\%) decrease of volume occurring quite rapidly between 1987 and 1991 all along the section except close to $90 \mathrm{~N}$ where there was no significant change. TWEFB note the coincidence of rapid decrease with extreme positive values of AO (Thompson and Wallace, 1998) and NAO (Hurrell, 1995) indices, and with decreased central Arctic sea level pressure (Walsh et al., 1996). The correspondingly weaker anticyclonic winds, leading to weakened Beaufort Gyre (cf. Kwok, 2000), may have allowed ice to be more freely advected across the central Arctic to Fram Strait (TWEFB). While the range of model results support broadly the description given by Kwok or by TWEFB, we encounter a vexing discrepancy as model runs sampled at the times and locations of TWEFB yield erratic results from $8 \%$ loss to $4 \%$ gain where TWEFB find 32\% loss. Over the analysis domain at the TWEFB times, losses from 1987 to 1991 range from $3 \%$ to $9 \%$, while this period stands at the beginning of a longer period (through about 1997) during which overall losses range from $16 \%$ to $25 \%$. We do not understand the discrepancy from TWEFB, and return in Section 5 to discuss this in the larger context of volume change during the 1990s. Here we summarise in Table 1 the several comparisons.

\section{Table 1.}




\begin{tabular}{|c|c|c|c|}
\hline Source & Data locations & Dates & Change of thickness \\
\hline Rothrock et al. 1999 & Rothrock et al. 1999 & Rothrock et al. 1999 & $-42 \%$ \\
\hline This study & Rothrock et al. 1999 & Rothrock et al. 1999 & $-25 \%$ to $-43 \%$ \\
\hline This study & Arctic domain & Rothrock et al. 1999 & $-12 \%$ to $-15 \%$ \\
\hline Wadhams Davis 2000 & Fram to $90 \mathrm{~N}$ & Sept, 1976 to 1996 & $-43 \%$ \\
\hline This study & Fram to $90 \mathrm{~N}$ & Sept, 1976 to 1996 & $-28 \%$ to $-73 \%$ \\
\hline This study & Arctic domain & Sept, 1976 to 1996 & $-27 \%$ to $-36 \%$ \\
\hline Winsor 2001 & Alaska to $90 \mathrm{~N}$ & May, 1991 to 1997 & $-9 \%$ \\
\hline This study & Alaska to $90 \mathrm{~N}$ & May, 1991 to 1997 & $-7 \%$ to $-24 \%$ \\
\hline This study & Arctic domain & May, 1991 to 1997 & $-10 \%$ to $-21 \%$ \\
\hline Tucker et al. 2001 & Alaska to $90 \mathrm{~N}$ & May, 1987 to 1991 & $-32 \%$ \\
\hline This study & Alaska to $90 \mathrm{~N}$ & May, 1987 to 1991 & $+4 \%$ to $-8 \%$ \\
\hline This study & Arctic domain & May, 1987 to 1991 & $-3 \%$ to $-9 \%$ \\
\hline
\end{tabular}




\section{WHY?}

\section{a. The wind did it.}

Whenever model results are reported, a concern must be how much depends upon uncertain detail of any model, and how much we can understand in a robust, physicallymotivated way. Studies, leading to the pattern such as in Figure 2, reveal that this is largely due to changing wind patterns interacting with a mobile ice cover. Do changes of winds explain the changed ice? Examining the history of wind prior to times of ice sampling, a question is: over how much prior time? Since we are not sure, we've varied the time window, ranging from a few winter months to the eight calendar months prior to September observations (for RYM evaluation). Results obtained for these different time windows are broadly similar and Figure 3 shows a representative difference between windstress prior to the latter $(1993,1996,1997)$ and earlier (1958, 1960, 1962, 1970, 1976) periods from RYM.

In fact the windstress differences in Figure 3 are themselves model-dependent insofar as the NCEP reanalysis products are model-based. We only suppose that plausible changes of windstress over the indicated periods resembled the pattern seen in the figure. Although ice response is complicated by nonlinear dynamics, qualitatively we can interpret ice distribution in Figure 2 in a quasilinear way, expecting difference ice to be forced by difference windstress while drifting somewhat to the right. The mean stress (not shown) acting on the difference ice contributes also. Figure 3 shows that, when submarines returned in 1993, 1996 and 1997 , changes of wind had plausibly expelled ice from the central Arctic mainly into the Canadian sector. If this is true then previously inferred rapid loss of ice volume, e.g. IPCC 2001, was mistaken due to undersampling, an unlucky combination of ever-varying winds and readily shifting ice.

Likewise we find variable wind forcing primarily responsible for ice loss along WD, Winsor and TWEFB sections. Both the rapid loss reported by WD and the mild non-loss 
reported by Winsor fall consistently within the range of model results. However, a very large loss reported by TWEFB between 1987 and 1991 is greater than we can account for over the ranges of wind forcing and model parameters we have studied. We return later to discuss issues of rapid ice loss during the early-mid-1990s in Section 5.

Concerning robustness, we've made further tests. To isolate the role of varying wind forcing from changing thermodynamic forcing, we have preformed two experiments. First windstress was assigned from its 52-year mean seasonal cycle while other atmospheric variables (temperature, humidity, precipitation, windspeed, etc.) evolved from their full timeseries. Second, atmospheric variables except windstress were assigned from their 52-year seasonal cycles while windstress evolved from its full timeseries. Strictly, dynamic and thermodynamic forcing are not separated in this way since forcing that modifies ice cover alters thermodynamic forcing, as described also by ZRS. However, timeseries of total ice volume, as well as specific patterns of thickness, were found to be more responsive to timeseries including windstress variability than to timeseries including other atmospheric variability.

We ask if the changes of windstress patterns as seen in Figure 3 are unusual or are part of larger patterns which may be related to AO or NAO indices. Timeseries of winter (Jan. - March) and 8-month (Jan. - Aug.) AO are shown in Figure 4 with the years of RYM analyses indicated. Averaged over the latter $(1993,1996,1997)$ and earlier $(1958,1960,1962,1970,1976)$ periods, the winter index was 1.9 points higher and the 8 -month index 0.6 points higher during the latter period. More cyclonic windstress seen in Figure 3 is characterized by more positive AO values seen in Figure 4.

\section{b. A natural model of Arctic ice variability.}

As we asked if the pattern of wind change seen in Figure 3 is unusual, we ask if the pattern of changed thickness in Figure 2 is unusual or typical of Arctic change. This question can be addressed within the context of model results by decomposing thickness variations (relative to mean annual cycle) over 52 years (1948 through 1999) into principal components or EOFs. A 
first EOF, accounting for $27 \%$ of thickness variance, is shown in Figure 5 along with the timeseries of its amplitude coefficient. Across the range of cases, patterns vary and the fractions of variance in first EOF range from $23 \%$ to $31 \%$.

Notably, the pattern of the EOF is like the pattern of change seen in Figure 2, which is also like Figure 10 of ZRS, enabling us to say that these patterns are not mere accidents of sampling but are representative of typical variability. An important point is contributed by PJ who average ice thickness over periods of positive AO, obtaining a pattern (Figure 4 of PJ) like our Figures 2 and 5. Hilmer (2001) also performed EOF analysis on model ice thickness, showing that the ice shift from the East Siberian Coast to north of the Canadian Archipelago is primarily related to the AO.

Timing of the RYM sampling, marked on Figure 5, shows the coefficient having shifted to more negative values during the latter period (1993, 1996, 1997), corresponding to thinning in the central Arctic with thickening in the Canadian sector. While there is negative trend over the 50 year timeseries of the amplitude coefficient, the trend is not fit by a linear slope but rather is dominated a jump to negative values occurring in 1989-1990 coincident with the strongly positive peak in AO. Although the section examined by TWEFB slices somewhat obliquely through the EOF pattern, the timeseries in Figure 5 and corresponding AO peak in Figure 4 support the view suggested by TWEFB.

\section{c. Timing is important.}

While Arctic change is sometimes characterized on decadal timescales, e.g. on the averaging intervals used by ZRS, it is clear from the timeseries in Figure 5 that temporal variability on much shorter timescales is relevant to inferences occasional submarine data. This is illustrated in Figure 6 where we imagine the 29 locations reported by RYM to have been occupied continuously over 50 years. The figure shows the average of thickness over those 29 locations with the timing of RYM analyses marked. It is interesting that, if one supposed a climatic trend toward reduced ice volume, then one might better realize the signal by extending the analysis interval. Yet if we only reset the five earlier cruises to just one year earlier (Sept 1957, 
1959, 1961, 1969, 1975) and the three latter cruises to one year later (Sept 1994, 1997, 1998), the modelled results would have showed $11 \%$ to $15 \%$ thinning rather than $25 \%$ to $43 \%$ over model cases or $42 \%$ per RYM. The caution here is about undersampling in time as well as biasing spatial patterns seen in previous figures.

\section{DISCUSSION}

Everywhere environments change, and ability to sample those changes is limited. Inferences from sparse observations can be unrepresentative. Additional information concerning atmospheric forcing together with the demand that inferences be physically consistent within the capability of modern ocean-ice-snow modeling helps constrain inferences.

Previous reports that Arctic sea ice volume decreased nearly by half in recent decades have been widely cited in popular media and scientific considerations, e.g., IPCC 2001. However, attempts to estimate a comprehensive history of Arctic sea ice volume are troubled with uncertainty. To help address uncertainty about forcing and about model representations of ocean-ice-snow physics, we have executed a range of experiments. Finding that patterns of ice thickness and of total volume are especially sensitive to assumed windstress, we have employed different estimates of windstress. Experiments have included stress from NCEP reanalysis, from estmated vector winds and windspeeds, and from monthly and daily sea level pressure utilizing empirical "geostrophic stress" formulae (Steiner et al., 2001). Model sensitivity was tested by different parameterizations in the ice and snow components and in air-sea exchanges and radiative transfers.

Over this range of tests we find, consistently with submarine data, with estimated forcing, and with physics of ocean-ice-snow interaction, that Arctic sea ice volume has decreased more slowly that was hitherto reported. Previous inferences of rapid loss are attributed to undersampling, as varying windstress forced a natural component of sea ice variability. In particular a dominant mode of variability, moving ice between the central Arctic and the Canadian sector, was missed by the timing and tracks of submarine surveys.

Estimated 50 year histories of Arctic ice volume are shown in Figure 7, including four 
methods of estimating windstress and a case using an alternative calculation of downward longwave radiation. While shapes of the curves are similar, differences of mean ice volume are obvious. Clearly no linear trend over 50 years is appropriate and it is interesting to observe that volume estimated in 2000 is close to the volume estimated in 1950. Importantly, none of the cases show losses of total ice volume exceeding 40\%. A robust characterization over the half century timeseries consists of increasing volume to mid-1960s, decadal variability without signficant trend from mid-1960s through mid-1980s, then a loss of volume from mid-1980s through mid-1990s. Timeseries of annual volume minima (lower panel) are similar to timeseries of annual means (upper panel) but with more interannual variability.

Model results from late 1980s through mid-1990s, showing steep decline with possible leveling off or recovery during the late 1990s, pose a new research challenge. These results (Figure 7) correspond with independent model results including ZRS (their Figure 11), HL (their Figure 1) and PJ (their Figure 5). Whereas observations reported by RYM, WD and Winsor fall within the range of plausible model results, we are confronted by the abrupt loss $(32 \%$ between 1987 and 1991) reported by TWEFB and not evidenced in our model. At this point, we can only say that over the range of model cases, total volume loss from 1987 to 1997 varies from $15 \%$ to 26\%. Most ice loss in the late 1980's and early 1990's was due to wind forced enhanced export via Fram Strait and southeast of Spitzbergen. Weaker net thermodynamic growth during 1987 to 1997 accounts for only 2\% to 4\% volume loss. However, in the later 1990's the model cases show below-average exports compensated by below-average net thermodynamic growth, results in moderate overall change. Detailed analyses of heat and freshwater budgets (ongoing research) through the 1990s, along with yet-unpublished data from submarine, from altimetric satellites (Seymour Laxon, personal communication), and from moored sonar (Humfrey Melling, personal communication) should refine future assessments.

\section{ACKNOWLEDGEMENTS}

We are grateful for assistance from Daniel Roberge and Nadja Steiner and for discussions with 
many colleagues. John Walsh, Peter Winsor and anonymous reviewers have provided valued critical advice. Terry Tucker and Yanling Yu kindly provided station data from submarine surveys. This research has been supported in parts by Climate Change Action Fund, Natural Resources Canada, by the Ocean Climate Program, Fisheries and Oceans Canada, and by the U. S. Office of Naval Research. 


\section{APPENDIX}

Because results in this paper are model-dependent, specifics of the model are listed below with focus upon some of the terms affecting energy balance in sea ice. The model follows Nazarenko et al. (1998), here incorporating parameterisations of all surface fluxes with no restoring terms. The ocean is based on the GFDL Modular Ocean Model (Bryan, 1969; Pacanowski, 1995) with 0.5 arc-degree grid spacing under grid rotation after Eby and Holloway (1994). Vertical resolution is at 29 levels varying from $10 \mathrm{~m}$ to $4350 \mathrm{~m}$. A flux-corrected transport scheme after Gerdes et al. (1991) is used for tracer advection and eddy-topography interactions are represented by the neptune parameterisation (Holloway, 1992).

The domain has open boundaries with assigned (non-varying) $0.8 \times 10^{6} \mathrm{~m}^{3} / \mathrm{s}$ inflow at Bering Strait, $1.0 \times 10^{6} \mathrm{~m}^{3} / \mathrm{s}$ outflow through Baffin Bay and $0.2 \times 10^{6} \mathrm{~m}^{3} / \mathrm{s}$ net inflow through the Greenland-Norwegian Sea. On inflow, water properties are assigned from a climalogical seasonal cycle from PHC (Steele et al., 2001). Thus we do not, in the present study, consider possible changes of inflowing temperature and volumes in the Greenland-Norwegian Sea. However, flows from the Greenland-Norwegian Sea into the Arctic via Fram Strait and the Barents Sea change in dynamic response to varying wind.

Surface fluxes are evaluated from bulk formulae.

Sensible heat flux: $\quad H=\square_{\mathrm{a}} \mathrm{c}_{\mathrm{a}} \mathrm{C} \mathrm{V}_{\mathrm{a}}\left(\mathrm{T}_{\mathrm{a}}-\mathrm{T}_{\text {surf }}\right)$

Latent heat flux: $\quad L E=\square_{\mathrm{a}} \mathrm{L} \mathrm{C} \mathrm{V}$ a $\left(\mathrm{q}_{\mathrm{a}}-\mathrm{q}_{\text {surf }}\right)$

where $\mathrm{q}_{\text {surf }}=\square \mathrm{e}_{\mathrm{s}}\left[\mathrm{p}-(1-\square) \mathrm{e}_{\mathrm{s}}\right]^{-1}$ and $\mathrm{e}_{\mathrm{s}}=611 \exp \left\{\mathrm{a}\left(\mathrm{T}_{\text {surf }}-273.16\right) /\left(\mathrm{T}_{\text {surf }}-\mathrm{b}\right)\right\}$.

Incoming longwave radiation, after König-Langlo and Augstein (1994): 


$$
L W=\square \mathrm{T}_{\mathrm{a}}^{4}\left(.765+.22 \mathrm{c}^{3}\right)
$$

Shortwave radiation:

$$
S W=\mathrm{S} \cos ^{2} \mathrm{Z}\left\{(\cos \mathrm{Z}+2.7) \mathrm{e}^{*} 10^{-5}+1.085 \cos \mathrm{Z}+0.1\right\}^{-1}\left(1-0.6 \mathrm{c}^{3}\right)(1-\square \text { surf })
$$

where $\mathrm{e}=\mathrm{p} \mathrm{q}_{\mathrm{a}}\left[\mathrm{q}_{\mathrm{a}}(1-\square)+\square\right]^{-1}$.

Ocean-ice heat flux: $F=\square_{\mathrm{w}} \mathrm{c}_{\mathrm{w}} \square\left(\mathrm{T}_{\mathrm{f}}-\mathrm{T}_{\mathrm{w}}\right)$ where $\mathrm{T}_{\mathrm{f}}=-0.0544 \mathrm{~S}_{0}+273.15$

Conductive flux through ice: $\quad G_{i}=\square_{\mathrm{i}}\left(\mathrm{T}_{\mathrm{f}}-\mathrm{T}_{\mathrm{i}}\right) \mathrm{h}_{\mathrm{i}}{ }^{-1}$

Conductive flux through snow: $\quad G_{s}=\square_{\mathrm{s}}\left(\mathrm{T}_{\mathrm{i}}-\mathrm{T}_{\mathrm{s}}\right) \mathrm{h}_{\mathrm{s}}{ }^{-1}$

Ice dynamics follow Hibler (1979) with prognostic equations for thickness and concentration. Momentum dynamics are nonlinear viscous-plastic. Both snow and ice thermodynamics are determined from heat budget calculations after Parkinson and Washington (1979) using their approximations for sensible and latent heat fluxes, outgoing longwave radiation, short wave radiation and conduction though ice and snow. Incoming longwave radiation is calculated after König-Langlo and Augstein (1994). Snow converts to ice when snow has sufficient weight to displace the ice surface below sea surface. Values of parameters cited above

\begin{tabular}{|c|c|c|c|}
\hline Parameter & Value & Units & Definition \\
\hline$\square_{\mathrm{i}}$ & 0.6 & none & albedo of frozen (cold) ice \\
\hline$\square_{\mathrm{s}}$ & 0.8 & none & albedo of frozen (cold) snow \\
\hline$\square_{\mathrm{w}}$ & 0.1 & none & albedo of liquid water \\
\hline$\square_{\text {surf }}$ & $\square_{\mathrm{i}}, \square_{\mathrm{s}}, \square_{\mathrm{w}}$ & none & albedo of water, ice or snow surface \\
\hline 0 & 0.622 & none & molecular weight water vapour/dry air \\
\hline Qw & 0.97 & none & long wave emissivity of seawater and ice \\
\hline Zs & 0.99 & none & long wave emissivity of snow \\
\hline$\square$ & 3. & $\mathrm{~m} /$ day & ice-ocean thermal exchange coefficient \\
\hline
\end{tabular}
and of other key parameters are listed below. 


\begin{tabular}{|c|c|c|c|}
\hline$\square_{\mathrm{i}}$ & 2.04 & $\mathrm{~W} \mathrm{~m}^{-2} \mathrm{~K}^{-1}$ & thermal conductivity of sea ice \\
\hline$\square_{\mathrm{s}}$ & 0.31 & $\mathrm{~W} \mathrm{~m}^{-2} \mathrm{~K}^{-1}$ & thermal conductivity of snow \\
\hline$\square$ & 4000. & $\mathrm{~m}$ & neptune length parameter \\
\hline$\square \mathrm{a}$ & 1.3 & $\mathrm{~kg} \mathrm{~m}^{-3}$ & density of air \\
\hline$\square_{\mathrm{w}}$ & 1026. & $\mathrm{~kg} \mathrm{~m}^{-3}$ & reference density of seawater \\
\hline$\square \mathrm{f}$ & 1000. & $\mathrm{~kg} \mathrm{~m}^{-3}$ & reference density of freshwater \\
\hline Dice & 910. & $\mathrm{~kg} \mathrm{~m}^{-3}$ & reference density of ice \\
\hline Đsnow & 330. & $\mathrm{~kg} \mathrm{~m}^{-3}$ & reference density of snow \\
\hline$\square$ & $5.67 \times 10^{-8}$ & $\mathrm{~W} \mathrm{~m}^{-2} \mathrm{~K}^{-4}$ & Stefan-Boltzmann constant \\
\hline $\mathrm{a}$ & 21.87 & none & empirical constant when ice is present \\
\hline $\mathrm{a}$ & 17.27 & none & empirical constant when ice is absent \\
\hline $\mathrm{A}_{\mathrm{h}}$ & 0. & $\mathrm{~m}^{2} \mathrm{~s}^{-1}$ & oceanic horizontal diffusion \\
\hline $\mathrm{A}_{\mathrm{m}}$ & 4.x10-4 $\mathrm{m}^{2} \mathrm{~s}^{-1}$ & ocea & c horizontal viscosity \\
\hline $\mathrm{b}$ & 7.5 & none & empirical constant when ice is present \\
\hline $\mathrm{b}$ & 35.86 & none & empirical constant when ice is absent \\
\hline c & input & none & fractional cloud cover \\
\hline$c_{a}$ & 1004. & $\mathrm{~J} \mathrm{~kg}^{-1} \mathrm{~K}^{-1}$ & specific heat of air \\
\hline$c_{\mathrm{w}}$ & 4190. & $\mathrm{~J} \mathrm{~kg}^{-1} \mathrm{~K}-1$ & specific heat of seawater \\
\hline $\mathrm{C}$ & $1.75 \times 10^{-3}$ & none & exchange coefs for heat and moisture \\
\hline $\mathrm{dt}$ & $4.32 \times 10^{4}$ & $\mathrm{~s}$ & model timestep \\
\hline $\mathrm{K}_{\mathrm{h}}$ & 1. $\times 10^{-5}$ & $m^{2} s^{-1}$ & oceanic vertical diffusion \\
\hline $\mathrm{K}_{\mathrm{m}}$ & 1. $\times 10^{-3}$ & $\mathrm{~m}^{2} \mathrm{~s}^{-1}$ & oceanic vertical viscosity \\
\hline $\mathrm{L}_{\mathrm{v}}$ & $2.5 \times 10^{6}$ & $\mathrm{~J}$ kg-1 & latent heat of vaporization \\
\hline $\mathrm{L}_{\mathrm{s}}$ & $2.834 \times 10^{6}$ & $\mathrm{~J} \mathrm{~kg}^{-1}$ & latent heat of sublimation \\
\hline $\mathrm{p}$ & input & $\mathrm{Pa}$ & pressure \\
\hline $\mathrm{P}_{\mathrm{S}}$ & calculated & $\mathrm{ms}^{-1}$ & rate of snowfall \\
\hline q & input & $\mathrm{kg} \mathrm{kg}^{-1}$ spec & c humidity of air at $2 \mathrm{~m}$ \\
\hline $\mathrm{q}_{\text {surf }}$ & output & $\mathrm{kg} \mathrm{kg}^{-1}$ spec & c humidity at water, ice or snow surface \\
\hline $\mathrm{S}$ & 1353. & $\mathrm{~W} \mathrm{~m} \mathrm{~m}^{-2}$ & solar constant \\
\hline $\mathrm{S}_{\mathrm{i}}$ & 4. & $\mathrm{psu}$ & assigned salinity for sea ice \\
\hline $\mathrm{T}_{\mathrm{a}}$ & input & $\mathrm{K}$ & air temperature at $2 \mathrm{~m}$ \\
\hline $\mathrm{T}_{\text {surf }}$ & output & $\mathrm{K}$ & temperature at water, ice or snow surface \\
\hline $\mathrm{Q}_{\mathrm{i}}$ & $3.02 \times 10^{8}$ & $\mathrm{Jm}^{-3}$ & volumetric heat of fusion, ice \\
\hline$Q_{s}$ & $1.10 \times 10^{8}$ & $\mathrm{Jm}^{-3}$ & volumetric heat of fusion, snow \\
\hline
\end{tabular}




\section{REFERENCES}

Becker, P., 1995: The effect of Arctic river hydrological cycles on Arctic Ocean circulation. PhD thesis, Old Dominion University, Norfolk, Va.

Bourke, R. H. and R. P. Garrett, 1987: Sea ice thickness distribution in the Arctic Ocean. Cold Regions Sci. Tech., 13, 259-280.

Bourke, R. H. and A. S. Mclaren, 1992: Contour mapping of Arctic Basin ice draft and roughness parameters. J. Geophys. Res., 97, 17715-17728.

Carsey, F. D., 1982: Arctic sea ice distribution at end of summer 19731976 from satellite microwave data. J. Geophys. Res., VOL, 5809-5835.

Cavalieri, D. J., P.Gloersen, C. L. Parkinson, J. C. Comiso, and H. J. Zwally, 1997: Observed hemispheric asymmetry in global sea ice changes. Science, 278, 1104-1106.

Hilmer, M, 2001: A model study of Arctic sea ice variability. Ph.D. thesis. No.320., Institut für Meereskunde at the University of Kiel, Germany. ISSN 0341-8561, 157 pp.

Hilmer, M. and T. Jung, 2000: Evidence for a recent change in the link between the North Atlantic Oscillation and Arctic sea ice export. Geophys. Res. Lttr., 27, 989-992.

Hilmer, M. and P. Lemke, 2000: On the decrease of Arctic sea ice volume. Geophys. Res. Lttr., 27, 3751-3754.

Hurrell, J. W., 1995: Decadal trends in the North Atlantic Oscillation: regional temperatures and precipitation. Science, 269, 676-679.

IPCC 2001, Climate Change 2001: The Scientific Basis. Contribution of Working Group I to the Third Assessment Report of the IPCC. Cambridge University Press (in press)

Johannessen, O.M., E. V. Shalina, and M. W. Miles, 1999: Satellite evidence for an arctic sea ice cover in transformation. Science, 286, 1937-1939.

Kalnay, E., M. Kanamitsu, R. Kistler, W. Collins, D. Deaven, L. Gandin, M. 
Iredell, S. Saha, G. White, J. Woolen, Y. Zhu, M. Chelliah, W.

Ebisuzaki, W. Higgins, J. Janowiak, K. C. Mo, C. Ropelewski, J.

Wang, A. Leetma, R. Reynolds, R. Jenne, and D. Joseph, 1996: The

NCEP/NCAR 40-year Reanalysis Project. Bull. Amer. Met. Soc., 77, 437-470.

König-Langlo, G. and E. Augstein, 1994: Parameterization of the downward longwave radiation at the Earth's surface in polar regions.

Meteorologische Zeitschrift, 3, 343-347.

Kwok, R., 2000: Recent changes of the Arctic Ocean sea ice motion associated with the North Atlantic Oscillation. Geophys. Res. Lett, 27, 775-778.

McLaren, A. S., J. E. Walsh, R. H. Bourke, R. L. Weaver, and W. Wittman, 1992: Variability in sea-ice thickness over the North Pole from 1977 to 1990. Nature, 358, 224-226.

Nazarenko, L., G. Holloway and N. Tausnev, 1998: Dynamics of transport of 'Atlantic signature' in the Arctic Ocean. J. Geophys. Res., 103, 31003-31015.

Parkinson, C.L., D.J. Cavalieri, P. Gloersen, H.J. Zwally and J.C. Comiso, 1999: Arctic sea ice extents, areas and trends, 1978-1996. $J$. Geophys. Res., 104, 20,837-20,856.

Polyakov, I. V. and M. A. Johnson, 2000: Arctic decadal and interdecadal variability. Geophys. Res. Lttr., 27, 4097-4100.

Proshutinsky, A. Y. and M. A. Johnson, 1997: Two circulation regimes of the wind-driven Arctic Ocean. J. Geophys. Res., 102, 12493-12514.

Rothrock, D.A., Yu, Y. and Maykut, G.A., 1999: Thinning of the Arctic sea ice cover. Geophys. Res. Lttr., 26, 3469-3472.

Serreze, M., J. Walsh, F. Chapin, T. Osterkamp, M. Dyurgerov, V. Romanovsky, W. Oechel, J. Morrison, T. Zhang, and R.G. Barry, 2000; Observational evidence of recent changes in the northern high-latitude environment, Climate Change, 46, 159-207. 
Shy, T. L. and J. E. Walsh, 1996: North Pole ice thickness and association with ice motion history. Geophys. Res. Lttr., 23, 2975-2978.

Steele, M., R. Morley and W. Ermold, 2001: PHC, a global hydrography with a high quality Arctic Ocean. J. Clim., 14, 2079-2087.

Steiner, N., T. Sou, and G. Holloway, 2001: Estimation of Arctic wind speeds and stresses with impacts on ocean-ice-snow modeling. J. Marine Sys., subm.

Thompson, D. W. J. and J. M. Wallace, 1998: The Arctic Oscillation signature in the wintertime geopotential height and temperature fields. Geophys. Res. Lttr., 25, 1297-1300.

Tucker, W. B., J. W. Weatherly, D. T. Eppler, L. D. Farmer and D. L. Bentley, 2001: Evidence for rapid thinning of sea ice in the western Arctic Ocean at the end of the 1980s, Geophysical Research Letters, 28, 2851-2854.

Vinnikov, K., Robock, A., Stouffer, R.J., Walsh, J.E., Parkinson, C.L. Cavalieri, D.J., Mitchell, J.F.B., Garrett, D. \& Zakharov, V.F., 1999): Global warming and northern hemisphere sea ice extent. Science, 286, 1934-37.

Wadhams, P., 1990: Evidence for thinning of the Arctic ice cover north of Greenland. Nature, 345, 795-797.

Wadhams, P., 1997: Ice thickness in the Arctic Ocean: the statistical reliability of experimental data. J. Geophys. Res., 102, 27951-27959.

Wadhams, P. and N. R. Davis, 2000: Further evidence of ice thinning in the Arctic Ocean. Geophys. Res. Lttr., 27, 3973-3975.

Walsh, J. E., W. L. Chapman and T. L. Shy, 1996: Recent decrease of sea level pressure in the central Arctic. J. Clim., 9, 480-486.

Winsor, P., 2001: Arctic sea ice thickness remained constant during the 1990s. Geophys. Res. Lttrs, 28, 1039-1041.

Zhang, J., D. Rothrock and M. Steele, 2000: Recent changes in Arctic sea ice: the interplay between ice dynamics and thermodynamics. J. Clim., 13, 3099-3114. 



\section{FIGURE CAPTIONS}

Figure 1. 52 year (1948 through 1999) annual mean ice thickness is shown within a subset of the model domain used for subsequent analyses. (Ice field is blanked outside the analysis region.) Locations of data used by RYM, WD, Winsor and TWEFB are marked. The case shown in Figures $1-2-3$ and 5 is from windstress calculated from $10 \mathrm{~m}$ vector wind and from daily windspeed.

Figure 2. Change of ice thickness between latter (Sept. 1993, 1996, 1997) and earlier (Sept. 1958, 1960, 1962, 1970, 1976) periods are shown with locations 1 through 29 from RYM for the case shown in Figure 1.

Figure 3. Difference of 8-month-mean (Jan. - August) windstress, averaged over 1993, 1996, 1997 minus the average over 1958, 1960, 1962, 1970, 1976 for the case shown in Figure 1.

Figure 4. Timeseries of 3-month (Jan. - March, dashed line) and 8-month (Jan. - August, solid line) mean AO index, with the years of RYM submarine data indicated.

Figure 5. First EOF of ice thickness variation (upper panel) and timeseries of its amplitude coefficient (lower panel) for the case shown in Figure 1.

Figure 6. Timeseries of average ice thickness at 29 locations shown in Figure 2 for three methods of windstress estimation: (a) reanalysis stress, dashed; (b) geostrophic windstress from monthly sea level pressure adjusted for daily windspeed, solid; and (c) windstress from $10 \mathrm{~m}$ vector wind, dotted. Samples at RYM times are marked.

Figure 7. Timeseries of total ice volume from four cases in which windstress is estimated from (a) reanalysis stress, dashed; (b) geostrophic windstress from monthly sea level pressure adjusted for daily windspeed, solid; (c) windstress from 10m vector wind, dotted., and (d) geostrophic 
stress from daily sea level pressure without windspeed adjustment, dash-dot. Also included is case (e) using downward longwave radiation after Parkinson and Washington (1979), dash-tripledot. The upper panel shows annual mean volume; the lower panel shows annual minimum volume. 